\title{
DEVELOPMENT OF A SYSTEM FOR MEASURING VOLUME OF EARTH TRANSPORTED ON A BARGE USING DIGITAL CAMERAS
}

\author{
Masaharu MASUTANI \\ Institute of Technology \\ PENTA-OCEAN CONSTRUCTION CO.,Ltd \\ 1534-1Yonku-cho Nasushiobara-shi,Tochigi \\ 329-2746,JAPAN
}

\author{
Hideki SUGIMOTO \\ Institute of Technology \\ PENTA-OCEAN CONSTRUCTION CO.,Ltd \\ 1534-1Yonku-cho Nasushiobara-shi,Tochigi \\ 329-2746,JAPAN
}

\begin{abstract}
To measure the volume of earth on the barge accurately and efficiently, a system was developed for accepting earth using digital cameras. The developed system has been applied at actual sites. The system measures the volume of earth on the barge using the technique of aerial photogrammetry. Stereo images are taken by two digital cameras that are installed above the hold of the barge. The images are subjected to stereo matching using personal computers to obtain the three-dimensional shape of the surface of the earth loaded on the barge and calculate the volume of the earth. This paper describes the principle of measurement, provides a system overview and reports the results of verification of system accuracy.
\end{abstract}

Keywords: digital cameras, aerial photogrammetry, measuring volume,three-dimensional coordinates

\section{Background of system development}

Numerous large-scale construction projects require techniques for shortening the construction period by rapidly executing large amounts of construction work and for reducing costs to meet social demand. Against such a background, we have developed a system for measuring the volume of earth on the barge to shorten the cycle of material dumping during the large-scale land reclamation for bayside airports.

The volume of earth on the barge has been measured manually using staffs and measuring tapes or obtained based on the mean draft of the hopper barge. Either method takes time for measurement and leads to the suspension of earth unloading and dumping, so it requires improvements for shortening the cycle of earth dumping.

Methods have recently been developed to measure the volume of earth on the barge using multiple electrooptical distance meters or ultrasonic distance meters. Technical problems have, however, been pointed out in relation to the diffusion of waves emitted for measurement, spacing of sensors and the effects of vibration or deflection of installation platforms. Reducing costs is also required.

In order to solve the problems, a system has been developed that uses commercially available digital cameras and personal computers, and aerial photogrammetry technique to measure the volume of earth on the barge.

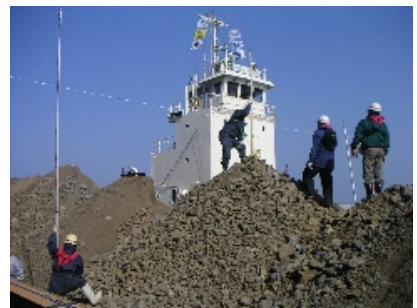

Photograph 1 Manual acceptance of earth

\section{Photograph 1 Manual acceptance of earth}

\subsection{Principle of measurement}

The system is based on a measurement principle known as the stereo image measurement used for aerial photogrammetry. Two visual sensors such as digital cameras are placed side by side to obtain stereo images of the object from different positions. Once the lines of sight have been determined based on the locations of camera stations and the gradients of visual sensors, three-dimensional coordinates of the object can be measured according to the triangulation principles. Calculation of three-dimensional coordinates is illustrated in Figure 1.

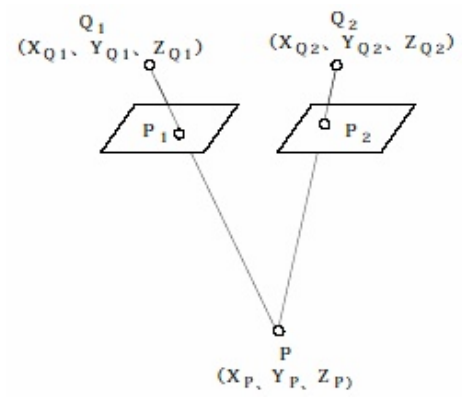

Figure 1 Calculation of three-dimensional coordinates

In the case where the camera stations from which two images are taken, $\mathrm{Q}_{1}\left(\mathrm{X}_{\mathrm{Q} 1}, \mathrm{Y}_{\mathrm{Q} 1}, \mathrm{Z}_{\mathrm{Q} 1}\right)$ and $\mathrm{Q}_{2}\left(\mathrm{X}_{\mathrm{Q} 2}, \mathrm{Y}_{\mathrm{Q} 2}, \mathrm{Z}_{\mathrm{Q} 2}\right)$, are known, if corresponding points on images, $\mathrm{P}_{1}$ and $\mathrm{P}_{2}$, are observed, the coordinates of point $\mathrm{P},\left(\mathrm{X}_{\mathrm{P}}, \mathrm{Y}_{\mathrm{P}}, \mathrm{Z}_{\mathrm{P}}\right)$, can be calculated at an intersection of lines connecting $Q_{1}$ and $Q_{2}$ to $\mathrm{P}_{1}$ and $\mathrm{P}_{2}$. In the system, $\mathrm{P}$ is a given point on the surface of the earth loaded on the barge.

For stereo matching $\mathrm{P}_{1}$ and $\mathrm{P}_{2}$ on the two images, a point with the highest similarity to the template window, a finite area encircling $P_{1}$ on the left image, is specified as $P_{2}$ after 
moving $\mathrm{P}_{2}$ in a designated area (search window) on the right image. Figure 2 gives an illustration.

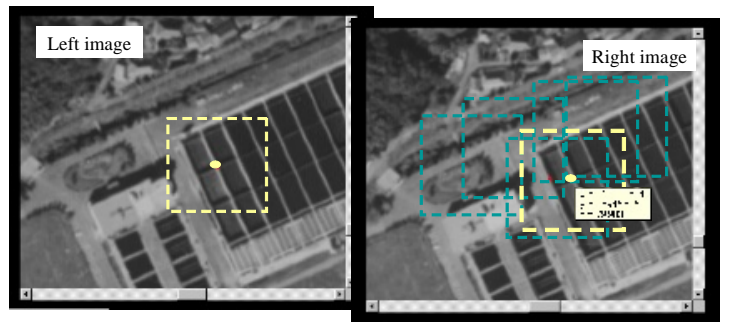

Figure 2 Stereo matching

The accuracy of stereo image measurement in the case where digital cameras are installed straight downward can be estimated based on the theoretical resolution per pixel. The horizontal and vertical elements of theoretical resolution are expressed as follows.

$\begin{array}{ll}\text { Horizontal element: } & \Delta X Y=\frac{p \cdot H}{f} \\ \text { Vertical element: } & \Delta z=\frac{p \cdot H^{2}}{f \cdot B}\end{array}$

where,

p: size of a pixel in the sensor

$\mathrm{H}$ : distance to the object to be measured

f: focal length of the lens

B: spacing of digital cameras

\subsection{Calculation of the volume of earth on the barge}

The three-dimensional shape of the surface of the earth is obtained by processing images taken by two digital cameras using computers. The shapes of the sides and bottom of the earth that are not captured in the images are obtained based on the dimensions of the hold of the barge and are combined three-dimensionally with the shape of the surface of the earth to calculate the shape of the earth loaded on the barge. The earth is cut into multiple cross sections at certain spacings and the volume of earth is obtained based on a mean cross sectional area.

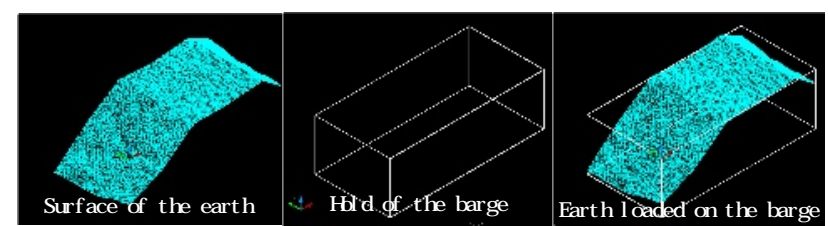

Figure 3 Calculation of the volume of earth on the barge

\section{System overview}

\subsection{System overview}

The system photographs the hold of the barge from above using two digital cameras and calculates the volume of the earth using the stereo image calculation method. The system has been installed in three manners according to the site condition. The system is installed on the ship loader in the case where the earth is loaded at one location. The volume of earth is measured by installing a cantilever derrick on the barge on the sea surface in the case where the earth is loaded at multiple locations. In the case where the earth is loaded at multiple locations but mooring the barge is difficult because construction takes place in a narrow sea area, the system is installed on the reclaimer barge. Different modes of system installation are shown in the following photographs.

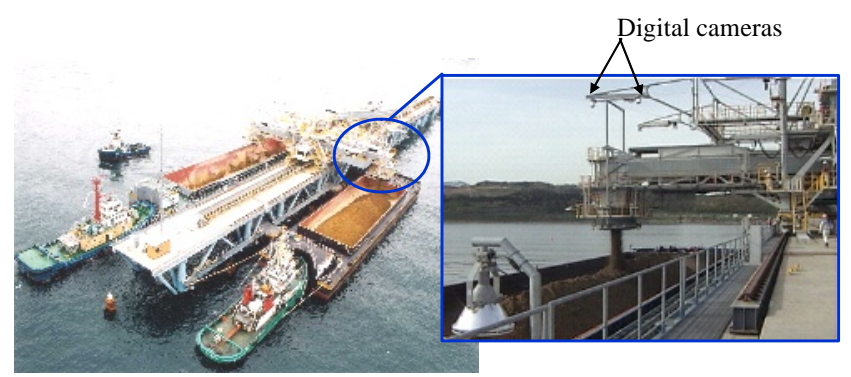

Photograph 2 Installing the system on a ship loader

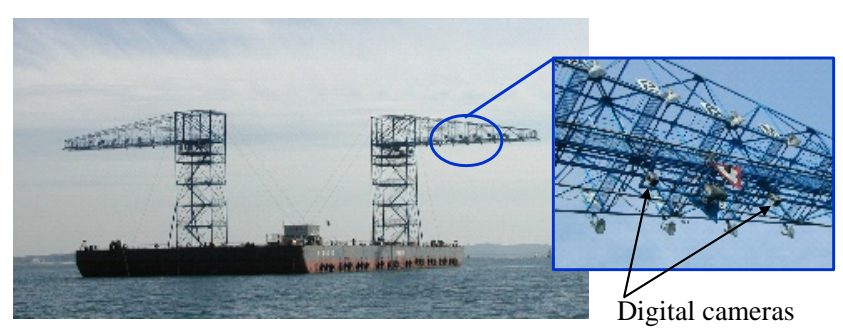

Photograph 3 Installing the system on the barge

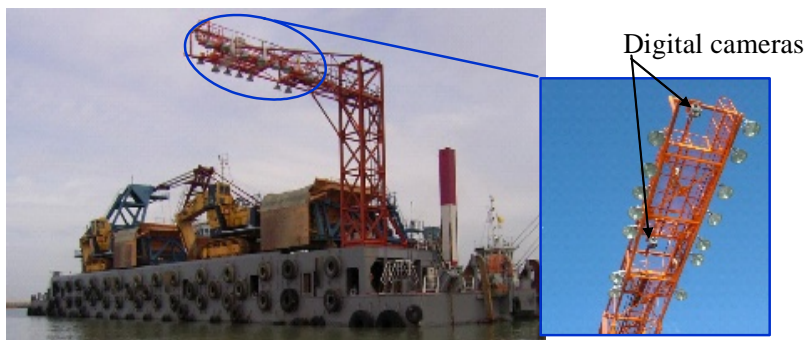

Photograph 4 Installing the system on the reclaimer barge

Basic equipment configuration and measurement flow are common to three modes of system installation. This paper describes the system installed on the ship loader. An illustration is given in Figure 4.

Two digital cameras are installed above the earth dumping inlet of the ship loader that is set on the offshore scaffolding to photograph the hold of the barge simultaneously. Taking photographs of the entire hold at once is difficult on a large barge. Then, the shutter is controlled based on the data of the movement of the ship loader, and the hold is photographed in sections. At the completion of photographing, image data stored in the internal memory units of digital cameras are transmitted via a fiber optic cable to a computer dedicated to analysis. After the analysis, the volume of the earth on the barge is calculated. The operator simply pushes the start and end buttons and verifies the analysis results throughout a series of processing. Thus, system operation has been automated. 


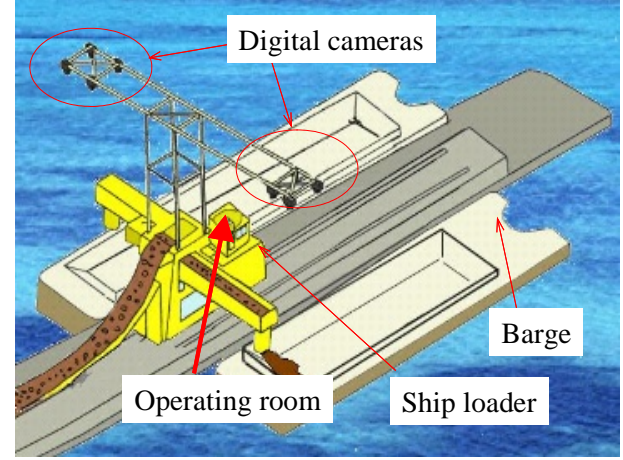

Figure 4 Installing the system on a ship loader

\subsection{System configuration}

Major system components are digital cameras installed at the earth damping inlet of the ship loader, photographing control equipment installed in the ship loader operating room and analysis equipment set in the earth acceptance office. Two sets of digital cameras were installed on either side of the ship (a total of eight cameras were installed) because barges came close to the ship loader on both sides and because the ship loaded moved either toward land or toward sea at the end of earth unloading to the barge. Figure 5 shows a system configuration.

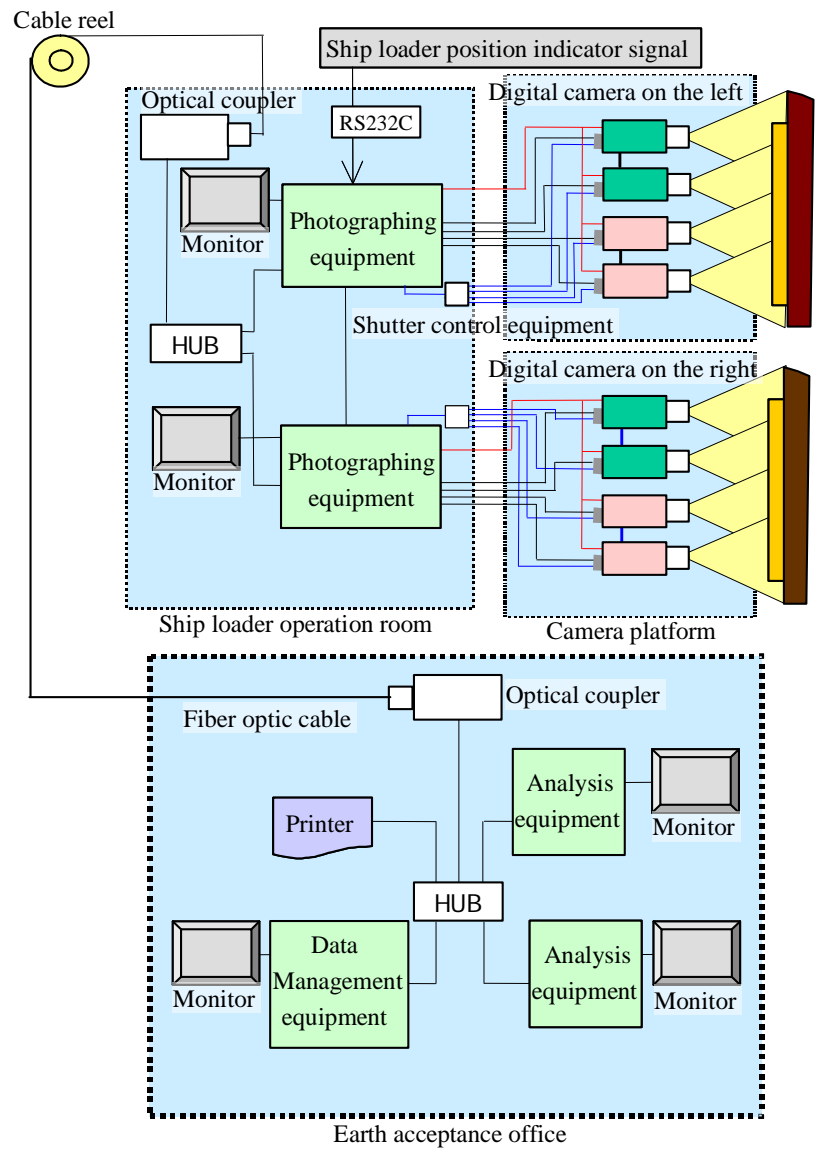

Figure 5 System configuration

\subsection{Analysis}

Major analysis methods include automatic slope correction, cross sectional shape measurement by stereo image measurement and construction of mosaics.

Automatic slope correction involves automatically extracting the edge (frame) of the photographed hold of the barge from images and correcting the slope or orientation of the barge based on the shape of the hold that is measured earlier. Automatic slope correction can enable any slope of the barge to be corrected to none. The error in measurement of the shape of the earth loaded on the barge is minimized because the slope is corrected based on the width of the frame of the hold. Figure 6 shows a frame of the hold extracted. Figure 7 illustrates automatic slope correction.

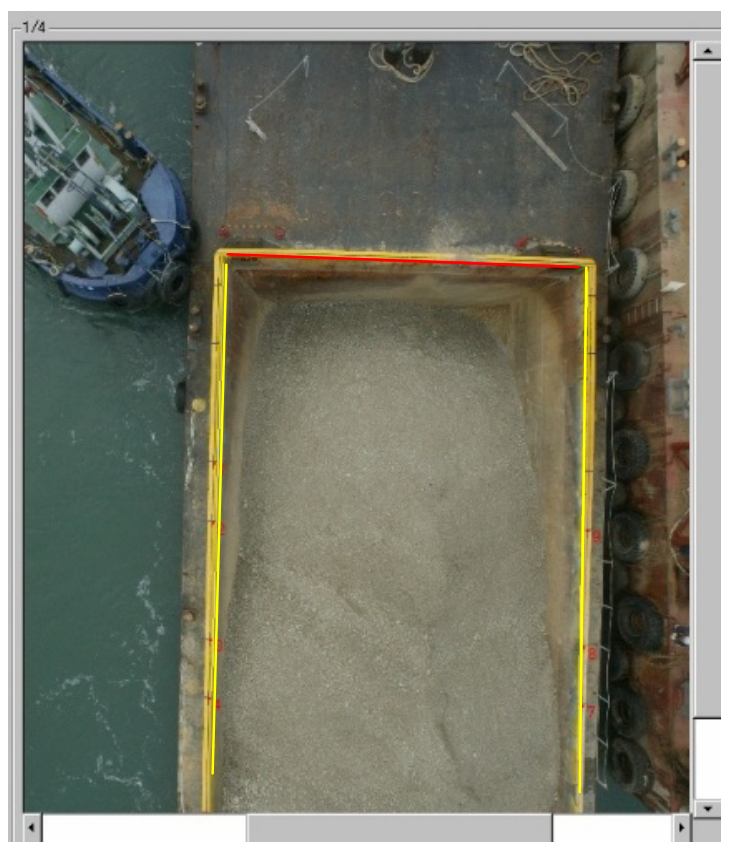

Figure 6 Frame of the hold extracted

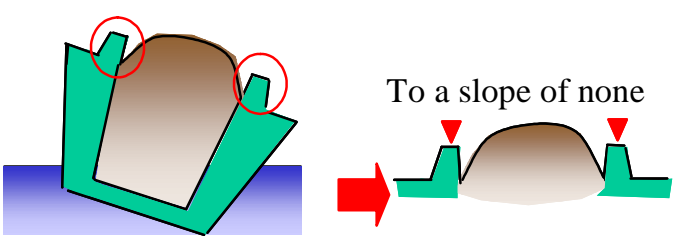

Figure 7 Automatic slope correction

In cross sectional shape measurement by stereo image measurement, cross section lines are drawn on the right and left frames of the hold at designated spacings. Measurement points are set on each cross section line at spacings of $20 \mathrm{~cm}$, and $\mathrm{X}$ and $\mathrm{Y}$ coordinates are obtained. Then, vertical exploration is carried out at the $\mathrm{X}$ and $\mathrm{Y}$ coordinates to obtain three-dimensional coordinates.

Finally, the shape of the cross section is used to calculate the volume of the earth based on the mean cross sectional area. Figure 8 shows a result of cross sectional shape calculation. 


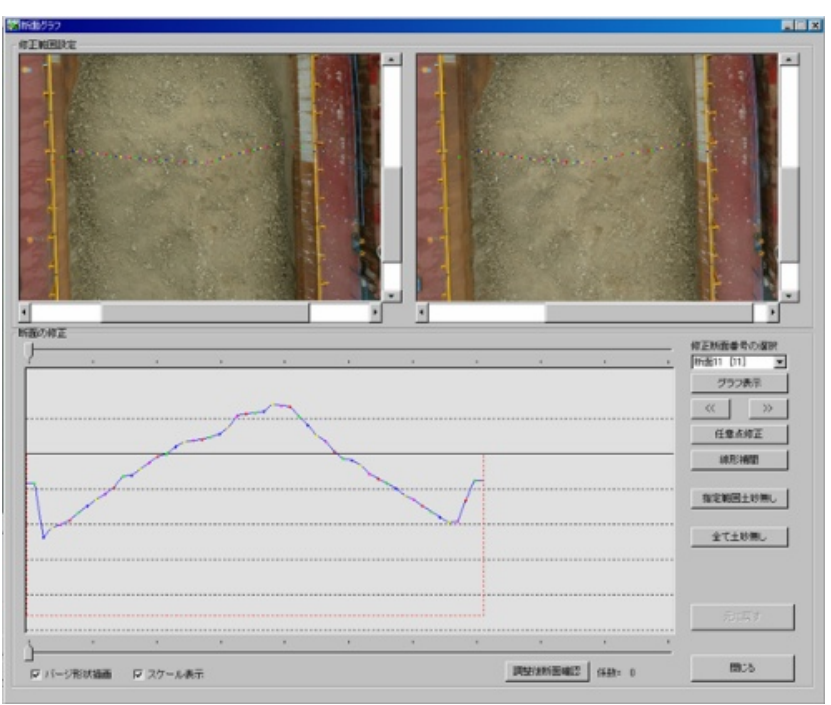

Figure 8 Result of cross sectional shape calculation

Mosaic construction means making a composite picture of photographs of individual sections of the hold of the barge. A single image of the entire hold is made by automatically extracting the same points on two continuous images in an overlapping area using analytical equipment, and images are combined automatically to form a single image. The composite image can be used to confirm the loading condition when accepting the earth. Figure 9 shows how a mosaic is constructed and Figure 10 shows a composite image.

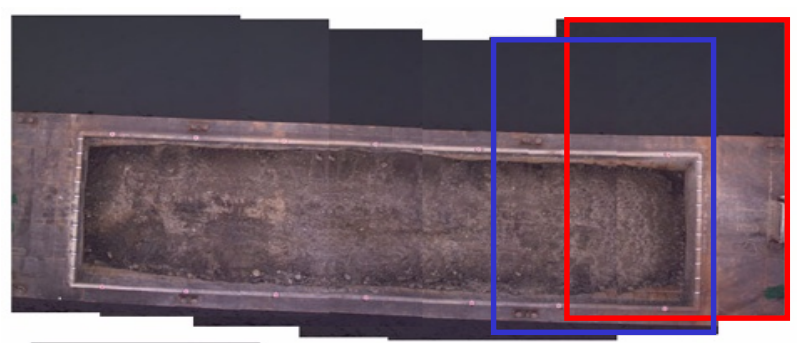

Figure 9 Construction of a mosaic

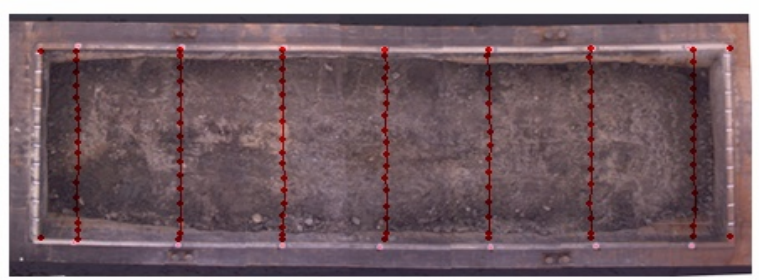

Figure 10 A composite photograph

\subsection{Processing of measurement results}

Results of measurement of the volume of earth on the barge can be used to prepare forms indicating the total volume per barge, and daily or weekly total volume. The form indicating the total volume per barge can present both the shape of typical cross section and a a composite photograph showing the loading condition that was obtained through mosaic construction. Figure 11 shows a form output for a barge.

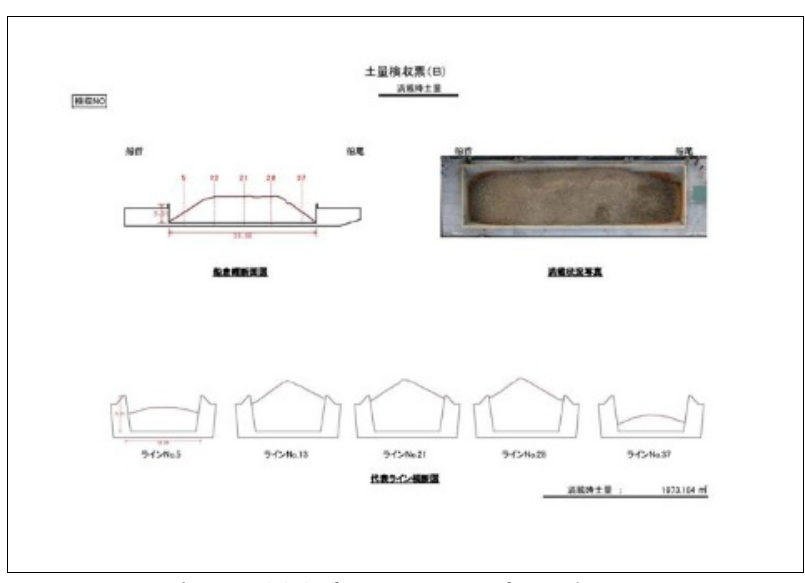

Figure 11A form output for a barge

\section{Verification of accuracy}

4.1 Verification of accuracy with a test scale

The measurement accuracy of the system was verified using a test scale with four targets. Targets were arranged as shown in Figure 12. Relative horizontal and vertical positions of targets were obtained based on the three-dimensional coordinates of the center of the target for comparison with actual relative positions. Photograph 5 shows a test scale. Figure 13 shows a measurement screen.

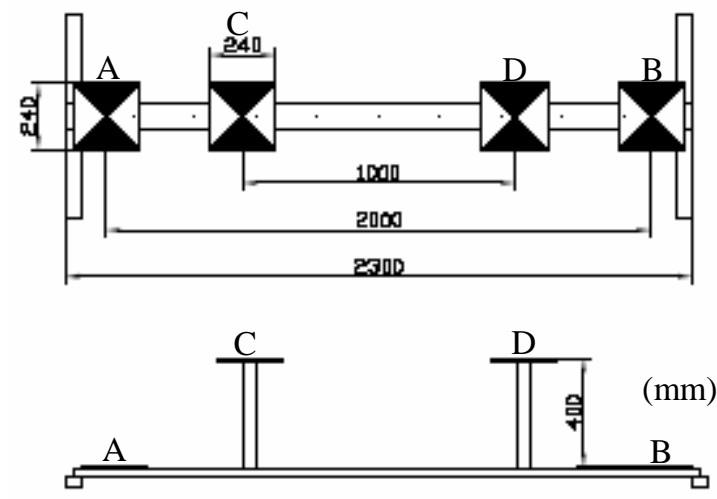

Figure 12 Dimensions of the test scale

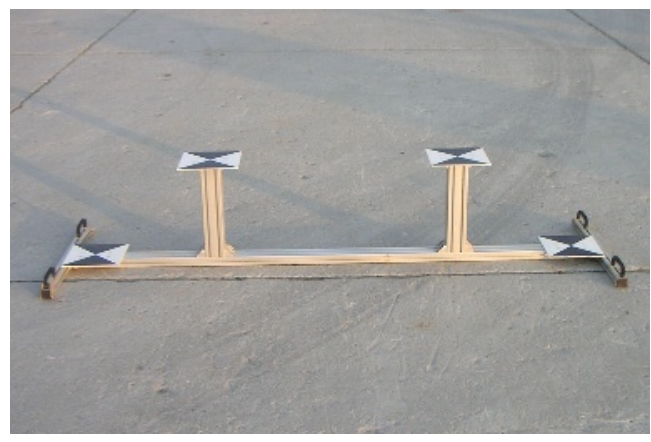

Photograph 5 Test scale 


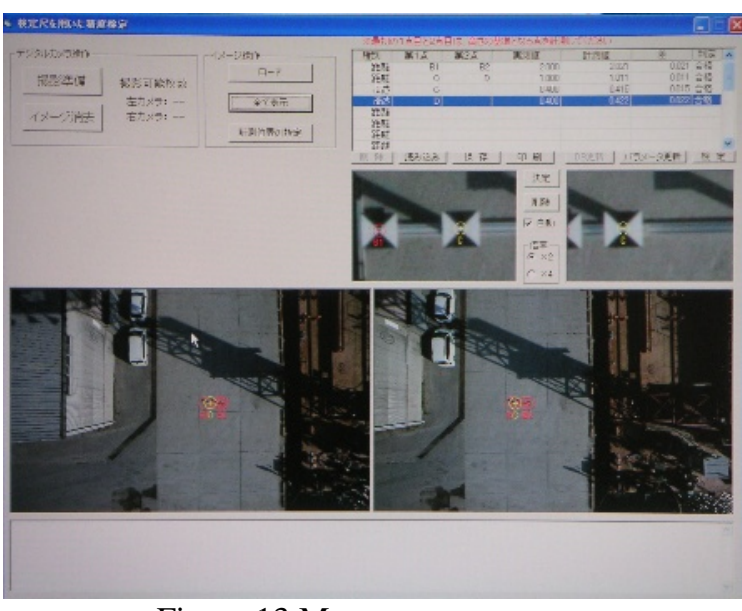

Figure 13 Measurement screen

Positions of digital cameras and the test scale during photographing are shown in Figure 14.

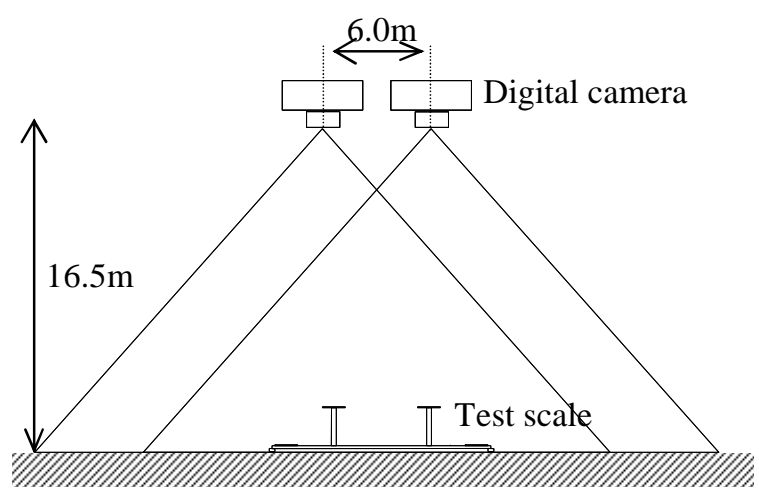

Figure 14 Positions of digital cameras and test scale

The theoretical accuracy is expressed by equations (1) and (2) by substituting a size of a pixel in the digital camera (p) of $9 \mu \mathrm{m}$, a distance to the object to be measured (H) of $16.5 \mathrm{~m}$, a focal length of the lens (f) of $14 \mathrm{~mm}$ and a spacing of digital cameras (B) of $6.0 \mathrm{~m}$.

Horizontal element: $\Delta X Y= \pm 10.6 \mathrm{~mm}$

Vertical element: $\quad \Delta z= \pm 28.5 \mathrm{~mm}$

Allowable ranges of measurements were defined as shown below because the relative positions of two targets were measured in verification.

\section{Horizontal distance: $\quad-21.2 \leq \Delta X Y \leq 21.2 \quad \mathrm{~mm}$ \\ Vertical distance: $\quad-57.0 \leq \Delta z \leq 57.0 \quad \mathrm{~mm}$}

Measurements were taken five times to obtain horizontal distances $(1 \mathrm{~m}$ or $2 \mathrm{~m})$ and vertical distance $(0.4 \mathrm{~m})$ between targets. Measurement results were within the allowable ranges, so theoretical accuracy was achieved. Thus, the effectiveness of the stereo image measurement method used in the system was verified.
Table 1 Horizontal distance between $\mathrm{A}$ and $\mathrm{B}$

\begin{tabular}{|l|r|r|r|r|}
\hline & \multicolumn{2}{|c|}{ Between A and B } & (in millimeters) \\
\cline { 2 - 5 } & $\begin{array}{l}\text { Actual } \\
\text { distance :(1) }\end{array}$ & $\begin{array}{l}\text { Measured } \\
\text { distance :(2) }\end{array}$ & $\begin{array}{l}\text { Variance } \\
\text { :(1) - (2) }\end{array}$ & $\begin{array}{l}\text { Standard } \\
\text { deviation }\end{array}$ \\
\hline First measurement & 2000 & 1992 & 8 & \\
\hline Second measurement & 2000 & 1996 & 4 & \multirow{2}{*}{13.2} \\
\hline Third measurement & 2000 & 2021 & -21 & \\
\hline Fourth measurement & 2000 & 2015 & -15 & \\
\hline Fifth measurement & 2000 & 2017 & -17 & \\
\hline
\end{tabular}

Table 2 Horizontal distance between $\mathrm{C}$ and $\mathrm{D}$

\begin{tabular}{|l|r|r|r|r|}
\hline & \multicolumn{2}{|c|}{ Between C and D } & \multicolumn{2}{c|}{ (in millimeters) } \\
\cline { 2 - 5 } & $\begin{array}{l}\text { Actual } \\
\text { distance :(1) }\end{array}$ & $\begin{array}{l}\text { Measured } \\
\text { distance :(2) }\end{array}$ & $\begin{array}{l}\text { Variance } \\
\text { :(1) - (2) }\end{array}$ & $\begin{array}{l}\text { Standard } \\
\text { deviation }\end{array}$ \\
\hline First measurement & 1000 & 995 & 5 & \\
\hline Second measurement & 1000 & 994 & 6 & \multirow{2}{*}{9.1} \\
\hline Third measurement & 1000 & 1014 & -14 & 9.10 \\
\hline Fourth measurement & 1000 & 1010 & -10 & \\
\hline Fifth measurement & 1000 & 1008 & -8 & \\
\hline
\end{tabular}

Table 3 Vertical distance between A and C

\begin{tabular}{|l|r|r|r|r|}
\hline & \multicolumn{3}{|c|}{ Between A and C } & \multicolumn{2}{c|}{ (in millimeters) } \\
\cline { 2 - 5 } & $\begin{array}{l}\text { Actual } \\
\text { distance :(1) }\end{array}$ & $\begin{array}{l}\text { Measured } \\
\text { distance :(2) }\end{array}$ & $\begin{array}{l}\text { Variance } \\
\text { :(1) - (2) }\end{array}$ & $\begin{array}{l}\text { Standard } \\
\text { deviation }\end{array}$ \\
\hline First measurement & 400 & 412 & -12 & \\
\hline Second measurement & 400 & 406 & -6 & \multirow{2}{*}{6.0} \\
\hline Third measurement & 400 & 407 & -7 & \\
\hline Fourth measurement & 400 & 402 & -2 & \\
\hline Fifth measurement & 400 & 396 & 4 & \\
\hline
\end{tabular}

Table 4 Vertical distance between B and D

\begin{tabular}{|l|r|r|r|r|}
\hline & \multicolumn{3}{|c|}{ Between B and D } & \multicolumn{2}{c|}{ (in millimeters) } \\
\cline { 2 - 5 } & $\begin{array}{l}\text { Actual } \\
\text { distance :(1) }\end{array}$ & $\begin{array}{l}\text { Measured } \\
\text { distance :(2) }\end{array}$ & $\begin{array}{l}\text { Variance } \\
\text {.(1) - (2) }\end{array}$ & $\begin{array}{l}\text { Standard } \\
\text { deviation }\end{array}$ \\
\hline First measurement & 400 & 399 & 1 & \\
\hline Second measurement & 400 & 410 & -10 & \\
\hline Third measurement & 400 & 402 & -2 & 6.1 \\
\hline Fourth measurement & 400 & 409 & -9 & \\
\hline Fifth measurement & 400 & 414 & -14 & \\
\hline
\end{tabular}

4.2 Verification of accuracy of measurement of the volume of earth loaded on the barge

The volume of the earth on the barge was measured to verify the accuracy of measurement. The volume of earth that was manually accepted (Photograph 1) was employed as a base for the volume of earth on the barge. For verification of accuracy measurement, ordinary closed box type barges with a loading capacity of 2,000 to $3,000 \mathrm{~m}^{3}$ were used. Photograph 6 shows a barge for which measurement accuracy was verified.

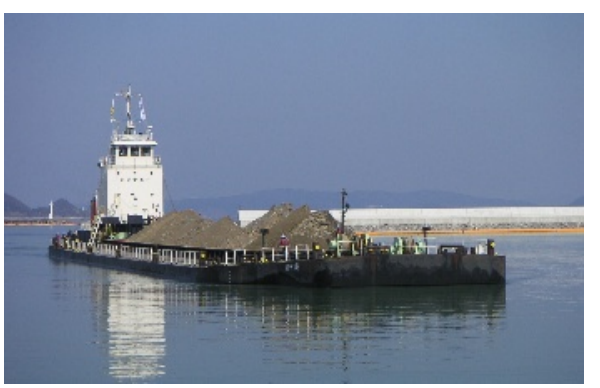

Photograph 6 Barge for which volume measurement accuracy was verified (with a loading capacity of 3,000 $\mathrm{m}^{3}$ ) 
Accuracy of measurement was verified using 24 barges. Measurement results are listed in Table 5.

Table 5 Results of measurement of earth

\begin{tabular}{|l|r|r|r|r|}
\hline & $\begin{array}{c}\text { Base } \\
\text { volume } \\
\left(\mathrm{m}^{3}\right):(1)\end{array}$ & $\begin{array}{c}\text { Measured } \\
\text { volume }\left(\mathrm{m}^{3}\right) \\
:(2)\end{array}$ & $\begin{array}{c}\text { Variance } \\
\left(\mathrm{m}^{3}\right):(1)-(2)=(3)\end{array}$ & $\begin{array}{r}\text { Percentage } \\
\text { of variance } \\
:(3) / 1\end{array}$ \\
\hline Barge 1 & 1558.4 & 1562.5 & -4.1 & $-0.3 \%$ \\
\hline Barge 2 & 1636.3 & 1634.4 & 1.9 & $0.1 \%$ \\
\hline Barge 3 & 1488.1 & 1484.5 & 3.6 & $0.2 \%$ \\
\hline Barge 4 & 1878.9 & 1889.0 & -10.1 & $-0.5 \%$ \\
\hline Barge 5 & 1948.7 & 1963.7 & -14.9 & $-0.8 \%$ \\
\hline Barge 6 & 1805.1 & 1790.7 & 14.4 & $0.8 \%$ \\
\hline Barge 7 & 2268.0 & 2294.3 & -26.3 & $-1.2 \%$ \\
\hline Barge 8 & 2744.2 & 2734.9 & 9.4 & $0.3 \%$ \\
\hline Barge 9 & 1797.2 & 1807.1 & -9.9 & $-0.5 \%$ \\
\hline Barge 10 & 2000.0 & 1956.3 & 43.8 & $2.2 \%$ \\
\hline Barge 11 & 3236.3 & 3227.1 & 9.2 & $0.3 \%$ \\
\hline Barge 12 & 2540.0 & 2486.5 & 53.5 & $2.1 \%$ \\
\hline Barge 13 & 3425.3 & 3376.0 & 49.3 & $1.4 \%$ \\
\hline Barge 14 & 2858.2 & 2834.0 & 24.1 & $0.8 \%$ \\
\hline Barge 15 & 2754.0 & 2732.4 & 21.6 & $0.8 \%$ \\
\hline Barge 16 & 2699.5 & 2675.8 & 23.7 & $0.9 \%$ \\
\hline Barge 17 & 1735.2 & 1726.7 & 8.5 & $0.5 \%$ \\
\hline Barge 18 & 1791.2 & 1777.3 & 13.9 & $0.8 \%$ \\
\hline Barge 19 & 1739.9 & 1748.9 & -9.0 & $-0.5 \%$ \\
\hline Barge 20 & 2268.0 & 2294.3 & -26.3 & $-1.2 \%$ \\
\hline Barge 21 & 2440.7 & 2418.5 & 22.2 & $0.9 \%$ \\
\hline Barge 22 & 2789.7 & 2818.2 & -28.5 & $-1.0 \%$ \\
\hline Barge 23 & 1991.7 & 1987.9 & 3.8 & $0.2 \%$ \\
\hline Barge 24 & 2255.3 & 2224.8 & 30.5 & $1.4 \%$ \\
\hline Total & 53649.8 & 53445.7 & 204.1 & $0.4 \%$ \\
\hline Standard deviation & & 22.7 & 0.9 \\
\hline
\end{tabular}

All of the measurements were close to the base value. Then, it was verified that the system provides accuracy equivalent to that of manual acceptance, a conventional measurement method.

Investigations were made of barges for which the base volume was different from the measurement by more than $2 \%$. The cause of the variance was ascribed to slight difference in cross sectional shape due to the difference in the number of measurement points on the cross sectional lines between measurement by the system and manual acceptance. The variance occurred because of an error in measurement in manual acceptance. Figure 15 compares cross sectional shapes identified by the system and in manual acceptance of earth.

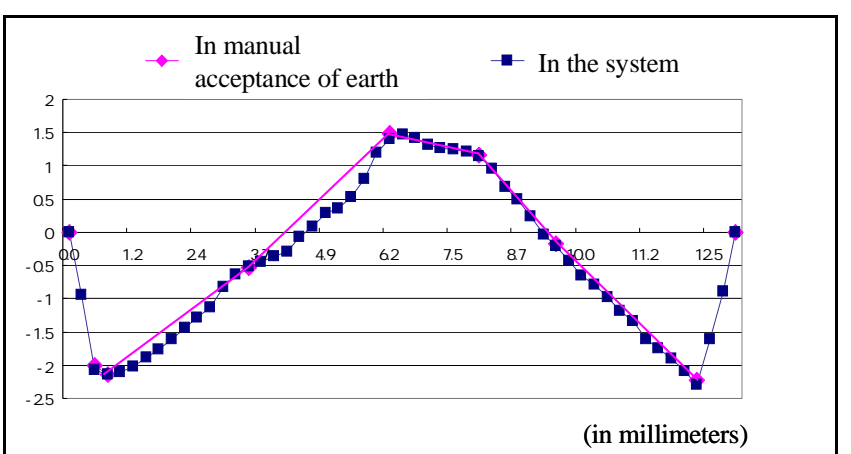

Figure 15 Comparison of cross sectional shapes

\section{Closing remark}

The system has been installed in three projects. The cumulative volume of earth measured amounts to 24 million $\mathrm{m}^{3}$. It was verified in the course of system operation that the system improves the safety of earth acceptance and efficiency of construction control over conventional acceptance methods.

In the future, technologies need to be developed to reinforce the system and reduce costs further. Reinforcing the present system requires the improvements of photographing systems and image processing methods and the realization of more convenient operation. To reduce costs, system configuration should be simplified and the installation of digital camera platforms should be considered. It is hoped that the system will be improved by pursuing such goals.

\section{References}

[1]Takahashi,M et.al.,'Development of the Measurement for the Quantity of Soil System by Digital Camera(Part 1 Outline of System and Inspection of Measurement Accuracies)",Technical Report of Penta-Ocean Construction Co.,Ltd vol.29,pp.45-50(Oct.1999) [2]Masutani,M et.al.,'Development of the Measurement System for the Quantity of Soil by Digital Camera(Part 2 Practical Use of a System)",Technical Report of Penta-Ocean Construction Co.,Ltd vol.35,pp.91-95 (Nov.2005) 